\title{
TRADICIÓN Y MELODISMO EN EL GÉNERO CHICO: LA PRODUCCIÓN LÍRICA DE JOSÉ SERRANO
}

\author{
TRADITION AND MELODISM IN THE GÉNERO CHICO: \\ THE MUSICAL SCENIC PRODUCTION OF JOSÉ SERRANO
}

\author{
José Salvador Blasco Magraner \\ Universitat de València \\ Francisco Carlos Bueno Camejo \\ Universitat de València \\ Fernando Torner Feltrer
}

Conservatorio Profesional de Música de Torrent

\begin{abstract}
Resumen
El presente artículo analiza los rasgos característicos de la obra lírica del maestro José Serrano Simeón, probablemente el compositor de zarzuelas más relevante del siglo XX, así como las opiniones que la crítica especializada de la época llevó a cabo sobre su insigne producción. La riqueza melódica de sus obras, que tenía su origen en la música popular española, la variedad rítmica de las mismas y su sencilla y eficaz instrumentación son tan sólo algunos de los rasgos más representativos de su magna obra.
\end{abstract}

\section{Palabras clave}

José Serrano, Zarzuela, Crítica, Prensa, Tipología teatral, Música popular, Partitura.

"No deja de ser original el modo de escribir ó, si queréis mejor, el sistema de trabajo que Serrano emplea, pues mientras los demás compositores, como es lógico, se ciñen y se sujetan á las situaciones y ponen en solfa los cantables que les da el libretista, él, en cambio, prescinde de todo y compone á su antojo coros, dúos, canciones y cuanto se le ocurre, lo apunta en el cuaderno, y el libretista es quien se encarga de aprovechar aquello como pueda ó sepa. Todo menos ceñirse al capricho ajeno ni al patrón que le den. Serrano, en eso, no se casa con nadie, dice que su inspiración es libre como el

\begin{abstract}
This article analyzes the characteristics of the lyrical work of the maestro José Serrano Simeon, probably the most important zarzuelas composer of the twentieth century, and the opinions that the critics of the time carried out on its flagship production. The melodic richness of his works, which had its origin in the Spanish popular music, the rhythmic variety of the same and simple and effective implementation are just some of the most representative of his magnum opus features.
\end{abstract}

\section{Keywords}

José Serrano, Zarzuela, Criticism, Newspapers, Theatrical type, Popular music, Score.

pájaro y que canta cuando quiere y lo que quiere, nunca lo que le mandan". ${ }^{1}$

\section{INTRODUCCIÓN}

José Serrano es un autor teatral que cuenta con una rica y variada producción lírica. Su catálogo asciende,

1 ASENSIO MAS (1911). 
aproximadamente, a unos cincuenta títulos que fueron compuestos, en su amplia mayoría, entre los años 1900 y 1930 .

El músico valenciano hizo su aparición en Madrid en la época en la que algunos de los más grandes autores, -como Manuel Fernández Caballero, Ruperto Chapí, Gerónimo Giménez y Federico Chueca-, eran los amos del teatro lírico y sus obras copaban la cartelera de los principales coliseos matritenses. Es en ese momento cuando se produce un relevo generacional y aparecen en la escena madrileña, además de Serrano, otros destacados autores como Vicente Lleó, Amadeo Vives o Quinito Valverde.

Los empresarios y los libretistas de entonces, como los de ahora, se mostraban reticentes a otorgar oportunidades a los jóvenes que llegaban a la capital de España sin más bagaje que las escasas pertenencias que viajaban con ellos. El camino para lograr el éxito, pues, distó de ser fácil. En apenas tres décadas Serrano pasó de ser un pobre músico que se resistía a regresar a Sueca, su ciudad natal, y luchaba por sobrevivir en la ciudad del Manzanares a convertirse en el compositor más popular de toda España.

En términos generales, se puede dividir la obra de José Serrano en tres periodos claramente diferenciados. El primero de ellos comprende la década de 1900-1909, esto es, desde El Motete hasta la composición de su famoso Himno de la Exposición de Valencia. Durante esta época Serrano apuesta por la continuación de la tradición y consagración del género chico, decantándose preferentemente por la composición de sainetes y zarzuelas; si bien, en algunas ocasiones, se sirve de otras modalidades teatrales, como el entremés, el cuento, la aventura cómico-lírica, la comedia lírica o el pasacalle cómico-lírico.

\section{RASGOS CARACTERÍSTICOS DE LAS ZARZUELAS DE JOSÉ SERRANO}

Llama la atención en esta primera fase compositiva el elevado número de obras que jalonan su amplia actividad creativa. Este hecho tiene su origen en las dificultades que cualquier autor teatral encontraba en sus inicios como profesional. Serrano tenía que abastecer continuamente a los coliseos con los que se hallaba ligado contractualmente. Por esta razón, es frecuente que el músico valenciano estrenase durante estos años entre cinco y seis piezas en una misma temporada teatral.

Las zarzuelas de este periodo se caracterizan por poseer un único acto, su temática es, por lo general, popular e intrascendente y no persiguen otro fin que agradar al público. Así, por ejemplo, El Motete (1900) cuenta las dificultades por las que pasa Mamerto, un músico de iglesia, para componer un motete que le han encargado, debido a las continuas molestias que le ocasionan sus vecinos. La Torería (1904) narraba el amor entre un banderillero llamado Posturitas, perteneciente a la cuadrilla del famoso matador de toros Tomás Hernández, y Rosario, hija de una tabernera. Tomás Hernández quiere también a Rosario, pero ésta le desprecia. En la primera corrida que actúa el nombrado matador, es alcanzado por el toro, pero Posturitas se interpone y es cogido por el feroz animal. Hernández agradece la acción de Posturitas y se ofrece a ser el padrino de la pareja. En El Pollo Tejada (1906) se describen las aventuras de un maduro conquistador que huye en globo de las garras de un marido desengañado y acaba aterrizando en una tierra lejana hasta recalar en el harén de un sultán.

A pesar de la sencillez de los libretos, es necesario recalcar la alta calidad de la música de este tipo de piezas. No es en absoluto baladí afirmar que se trata, quizá, de las partituras más frescas y espontáneas de toda la producción del insigne autor valenciano. La más cercana a la música popular española, de la que se nutre, aunque no siempre se adapta al gusto popular del momento.

Los libretistas con los que más colaboró fueron los hermanos Álvarez Quintero, Carlos Arniches, y García Álvarez, quienes llevaron a término el relevo generacional en el campo de la literatura dentro del teatro lírico. Se trataba, pues, de jóvenes autores a los que Serrano pudo imponer su particular forma de trabajar que consistía básicamente en que éstos se adaptasen a la música y no el compositor al libreto.

Riqueza, originalidad melódica y variedad rítmica son una constante en las partituras del primer Serrano. El ámbito vocal no suele presentar grandes dificultades, evitando saltos de gran interválica.

Hay que tener en cuenta que la búsqueda de material folclórico, como melodías populares, ritmos de moda y materias populares es una cualidad común entre los grandes compositores españoles de zarzuela.

Chapí, al que Serrano conoció en los tiempos en que éste estudiaba en el Conservatorio de Madrid, dijo a Vicente Peydró cuando éste acudió a su domicilio matritense de la calle del Arenal para que el gran maestro de Villena escuchase La Fiesta de la Campana antes de ser estrenada en el Teatro Apolo de Madrid:

Veo que se ha aprovechado usted del folklore montañés para dar carácter y sabor local a la obra. Es lo único que me interesaba saber. Los cantos populares son una cantera inagotable de hermosas melodías. ${ }^{2}$

2 PEYDRÓ DÍEZ (1931). 
El propio Vicente Peydró afirmaba, acerca de la carcelera que canta el personaje de Jesús en su magna zarzuela Las Carceleras, que había acudido a su copiosa biblioteca para inspirarse en la temática popular andaluza:

Yo había procurado documentarme, espigando en los cancioneros de mi copiosa biblioteca todos los temas populares andaluces que pudieran servirme para dar ambiente y sabor local a la zarzuela. ${ }^{3}$

Chapí colaboró con Serrano una única vez: El Amor en Solfa, zarzuela en un acto, con libro de los hermanos Serafín y Joaquín Álvarez Quintero. Serrano musicó el segundo y el tercer cuadro, mientras que Chapí se encargó del primero y el cuarto. Ha menester recordar que Chapí ya había elogiado al maestro Serrano al que definió como el autor lírico de más personalidad desde Barbieri.

Serrano tiene lo que corrientemente se llama sello propio; le aseguro que en el teatro lírico español, se salta de Barbieri a Serrano en lo tocante a tener personalidad. ${ }^{4}$

José Serrano también se nutría de la música popular española, su principal fuente de inspiración y verdadero sello de identidad de sus partituras. Él afirmaba que componía a base del ambiente popular que era, con toda certeza, el más bello y variado de cuantos conocía:

La música española es la más hermosa del mundo. Los cantos populares encierran tesoros de poesía que aún no se han explotado. Saint Saéns se admiraba de que en un recinto pequeño, como es el de España, pudiera haber tan diversos matices y tan varias fuentes de inspiración musical. Desde el zortzico vasco á la alborada gallega; de la sardana á la jota, hay muy pocos kilómetros; vea usted, sin embargo, cómo se diferencian. Andalucía, tiene, á mi juicio, la mayor riqueza de cantos más diversos: soleares, seguidillas y malagueñas son andaluzas. ¿Puede darse algo más distinto?

Estamos, pues, ante un caso paradigmático en el mundo de la zarzuela, muy dado a recoger y asimilar las influencias foráneas más diversas. En todo caso, Serrano sí asimila ritmos decimonónicos, como los valses, chotis y habaneras. Rehúye, en cambio, los bailes modernos que invadían el teatro tradicional como el fox-trot, tangos u otros bailes argentinos o el cake walk.

El periódico Las Provincias era de la opinión que la

3 BLASCO MAGRANER (2012): 280.

4 SAGARDIA (1972): 43.

5 La Esfera, 02.05.1914. música de Serrano se caracterizaba por su inspiración en la lírica popular. ${ }^{6}$ Eduardo López Chavarri aseguraba que Serrano era el único compositor que tenía lo principal que debía poseer un autor teatral, a saber, el don creador de melodías elegantes, bien sentidas, flexibles, claras y de bella prestancia. ${ }^{7}$ Rafael Díaz afirmaba que la fábrica de Serrano era fundamentalmente melódica, en la línea de la tradición de la ópera italiana, rechazando los declamados y huyendo de los saltos amplios y ásperos. ${ }^{8}$ A partir de 1910 Serrano se abre a influencias procedentes de la revista y de la opereta. Ha menester agregar que la decadencia del género chico y el auge de otras modalidades teatrales son decisivas para que se opere el cambio. Antonio Barrera y Marciano Zurita coinciden en que la opereta iba ganando terreno conforme va avanzando la primera década del siglo XX en detrimento del género chico:

$\mathrm{Al}$ doblar la esquina del siglo $\mathrm{XX}$, el género chico inicia su declive (...) entre 1910 y 1920 casi desaparece, para hacerlo totalmente en los años veinte.

$$
\text { (...) }
$$

Penella, Lleó, Calleja, Luna y Alonso, nuevos en esta época de avatares decadentes de nuestro género chico, no consiguen con su innegable ingenio enderezar algo que irremediablemente se ha torcido. Además optan por las modalidades más del gusto del público en esos momentos, como son la revista de espectáculo tendente a la sicalipsis y la opereta. ${ }^{9}$

Zurita explica que la opereta francesa y vienesa se impuso a principios de la nueva centuria y, por si esto no fuera poco, llegó La Corte de Faraón para acabar de conquistar el corazón del gran público..$^{10}$ Es entonces cuando entramos en el segundo tercio de la carrera de Serrano que se extiende hasta el año 1917, fecha en que el músico valenciano estrena La Canción del Olvido.

La revista, por su parte, puede considerarse un subgénero que forma parte del denominado teatro por horas, tan en boga durante el último tercio de la centuria decimonónica e inicios del siglo XX:

No sólo por su función sociológica, testimonio de las modas, gustos, cambios y acontecimientos (sociales, políticos y culturales) de toda una época sino por su morfología híbrida, a caballo entre el teatro musical y el
6 Las Provincias, 09.03.1941.
7 Las Provincias, 11.03.1941.
8 DÍAZ GÓMEZ (2006): 452.
9 BARRERA MARAVER (1983): 138-141.
10 ZURITA (1920): 103. 
declamado y, consecuentemente, todos los géneros que en ella vinieron a converger. ${ }^{11}$

Aunque la revista ha servido como reivindicación de aspectos culturales o políticos en muchos autores de origen valenciano o de cualquier otra región de España, Serrano no la utilizó para este fin. Los argumentos de sus obras, -poco o nada comprometidos con la situación política y económica de su tiempo-, y el tipo de música que componía, de gran riqueza melódica y sabor popular, favorecieron que sus zarzuelas perdurasen sin dificultad alguna en el repertorio lírico, incluso durante la dictadura franquista.

Así, por ejemplo, El Trust de los Tenorios (1910), con libreto de Carlos Arniches y Enrique García Álvarez, es la primera de las piezas afines al género de la revista. Aparecen once números musicales, muchos que en las obras precedentes, en los que destaca la relevancia del conjunto frente a los pequeños números protagonizados por uno o varios solistas. El cambio de decorados es notorio, como también lo es la variedad y riqueza del vestuario. Asimismo, la acción es tan trepidante como trivial e intrascendente. Así, en el caso de $E l$ Trust de los Tenorios, la trama nos presenta una sociedad de donjuanes en la que uno de ellos, Pedro Saboya, para no ser expulsado conquistará a la primera dama que se encuentre, siendo ésta la esposa del presidente del Trust.

Otro ejemplo de esta segunda fase es la zarzuela Si yo fuera Rey (1913), que posee diez números musicales y algunos momentos en que la presencia de la música es continua como, por ejemplo, desde la última escena del primer cuadro "Esta es la gruta que dijo el cuento" hasta la primera del tercero “¡Si yo fuera Rey!”.

Empero, no obstante, hay que reconocer que la música posee menor riqueza rítmica que las primeras producciones del compositor valenciano y las melodías pierden originalidad.

Las tipologías vocales sufren la influencia de la opereta y se tornan más blandas, aunque aparecen saltos de amplio ámbito interválico, circunstancia esta que no se daba en las piezas del primer periodo.

Durante estos años se evidencia una menor producción de Serrano; apenas dos obras por temporada en contra de las cuatro, cinco e incluso seis que engendraba cada año. Es entonces cuando el autor de El Motete comienza a adquirir fama de indolente, notoriedad esta que se agravará con el paso de los años debido a su incapacidad para concluir su ópera La Venta de los Gatos:

11 MONTIJANO RUIZ (2009): 34.
Tuvo fama de negligente, de vago, a pesar de haber dejado escritas cerca de un centenar de zarzuelas, himnos, marchas, etc. Los hermanos Álvarez Quintero - que con La mala sombra, Mal de amores y La reina mora - le habían abierto las puertas del triunfo, cuando le entregaron La venta de los gatos estaban desesperados porque pasaban meses, y aun años, sin que el maestro terminase la partitura. Serrano se excusaba siempre, diciéndoles que los números estaban terminados, pero que sólo faltaban los enlaces. Entonces, los Quintero, con su gracia andaluza y fina ironía, le enviaron un abultado sobre conteniendo cientos de recortes de periódicos en que en las notas de sociedad se leía: Enlace de la Srta. Tal con Don Fulano de Tal acompañado de una tarjeta en que le decían: Pepe, suponemos que con estos tienes ya bastantes Enlaces. ${ }^{12}$

A raíz del estreno de Los Claveles apareció en la sección de humor de la revista Nuevo Mundo, titulada "Colada semanal", unas líneas del periodista Luis de Tapia en las que Serrano no salía del todo bien parado:

"Pepe Serrano ha estrenado. Esto, aunque parezca otra broma, es verdad. Ha estrenado unos Claveles que se ven, se huelen, se tocan (en la orquesta), se oyen y gustan.

¡Es la música más maja

Y más sabia que se oyó!...

$¡ Y$ dicen que no trabaja

El vago del Perelló!...

(¡Es claro que mucho, no!). ${ }^{13}$

En un intento de justificarse ante la opinión pública por la desdichada fama de perezoso que le perseguía allá donde fuere, Serrano explicaba en la revista Nuevo Mundo los motivos de su escasa producción:

¡Perezoso! ¿Por qué? Pues porque no hago cada tres días un numerito de esos que se aplauden. Si yo quisiera y me diera la vena de hacer esa música, abastecería á todos los teatros. Y pondría en la puerta de mi casa este cartelito: Maestro Serrano. Hace números de jazz, de zarzuela, con prontitud y economía. Ilustraciones para sainetes...14

Con La Canción del Olvido (1916) llegamos a la época de madurez del compositor que concluye en 1930, fecha en que el autor da a conocer su último estreno en vida: la zarzuela La Dolorosa.
12 La Vanguardia Española, 11.07.1971.

13 Nuevo Mundo, 12.04.1929.

14 Nuevo Mundo, 22.02.1929. 
Es cierto que La Canción del Olvido se encuentra justo en el centro de toda la producción del gran maestro valenciano. Sin embargo, con esta obra Serrano alcanzó su cénit como autor de zarzuelas. A partir de entonces, se puede apreciar una mejor integración de la música en el drama, en detrimento de la espontaneidad que ofrecía en sus primeros trabajos:

A partir de entonces dio a la luz obras más reposadas y más trabajadas, que no hicieron sino intensificar sus rasgos como compositor, especialmente su característico don melódico. ${ }^{15}$

Es muy probable que este logro tenga su origen en la peculiar manera de trabajar de Serrano. Mientras el resto de compositores teatrales se ceñían a las situaciones que el libreto les exigía, el músico de Sueca prescindía de todo, componiendo a su antojo coros, dúos, cantables u otros tipos de números musicales que luego hacía llegar al libretista para que éste adaptase su texto a la música. De esta manera, Serrano quedaba libre para componer al dictado de su corazón, siguiendo su propia inspiración y evitando ceñirse al patrón de ningún escritor teatral. Los textos de los nuevos escritores de escena como Federico Romero o Luis Sevilla son supeditados a las partituras del maestro que tienen en la melodía al máximo exponente de su concepción lírica.

Quizá tenga razón y ese sea el secreto de sus mayores éxitos; lo cierto es que cuando le leen un libreto, Serrano echa mano al cuaderno de los apuntes. ¿Qué la obra tiene un dúo apasionado?, el músico abre el cuaderno y le dice al libretista:-Precisamente tengo aquí dos dúos amorosos completamente nuevos... Vamos á ver cuál de los tres nos sirve. Y los toca al piano y el libretista escoge. ${ }^{16}$

Los valses, chotos, habaneras y otros bailables son ahora sustituidos por amplios dúos, coros y cantables en los que la melodía lo impregna todo. El tratamiento vocal de esta última etapa destaca por una mayor exigencia técnica e interpretativa, teniendo en cuenta las producciones de zarzuela del momento.

La Canción del Olvido es una pieza fiel de este segundo periodo, por cuanto se aprecian claramente las influencias de la opereta centroeuropea. Serrano abandona el costumbrismo castizo madrileño para vincularse mejor con el más europeo de la opereta, sin dejar de lado la idiosincrasia del género. Sin embargo, apenas se percibe una influencia

15 DÍAZ GÓMEZ (2006): 446. 16 ASENSIO MAS (1911). extranjera en la música, ya que Serrano siempre rehusó la moda de incluir bailables extranjeros, así como exceder el marco del pequeño formato.

Los libretistas Federico Romero y Guillermo Fernández Shaw ofrecieron el libreto a Pablo Luna, quien lo rechazó. Serrano aceptó el encargo con la condición de que los tres actos de la zarzuela fuesen reducidos a sólo uno,- que fue incluido en la película que posteriormente filmó Televisión Española y fue premiada en Milán-, y, además, que otro cuadro fuese enteramente musical. Este último cuadro alcanzó los veinte minutos de duración.

El estilo vocal es cercano a la ópera italiana y la melodía se impone sobre todo lo demás. La exigencia vocal de los tres cantantes es bien notoria, tanto en tesitura, la del barítono alcanza prácticamente el límite superior de la misma (Fa sostenido), mientras la de la soprano lírica se acerca más bien a la de mezzo (de Si bemol grave a La agudo), como por su interpretación dramática. Serrano optó por la voz de barítono para el protagonista con el fin de buscar un color obscuro y grave, recurso éste frecuentemente utilizado por Verdi para dar autoridad y equilibrio a ciertos personajes.

Es aguda la observación que efectúa Eduardo López Chavarri al afirmar que a pesar de sentir Serrano una especial predilección por la música de Eduard Grieg y de componer la zarzuela La Sonata de Grieg, en la castiza música del músico valenciano no aparecía la influencia del maestro escandinavo, ni su sentido armónico ni la forma de sus combinaciones temáticas. Admirador de Chapí y experto conocedor de su obra, tampoco imitó el estilo del compositor de Villena. El personalísimo sello de Serrano llevaba su imprenta en la facilidad melódica y en los efectos siempre teatrales de sus eternos cantables.

La disminución en el ritmo de su producción en el último periodo compositivo dio como resultado obras más maduras y mejor acabadas que intensificaron sus rasgos como compositor, especialmente en lo que a la melodía se refiere. La espontaneidad y frescura de sus primeros trabajos fueron sacrificadas por un mayor equilibrio entre música y drama. La melodía es el elemento más destacable de esta postrera fase. Serrano la desarrolla hasta cotas inimaginables, creando ese sello tan personal y característico de sus piezas.

En La Dolorosa Serrano nos ofrece un horizonte nuevo. El carácter grave que en determinados momentos tiñe la escena deja entrever matices veristas en cuanto a la orquestación y al tratamiento de las voces. Es en estos momentos cuando el autor de La Reina Mora no se sirve de ningún referente folclórico, dando como resultado unos números musicales que recuerdan a la ópera por su unidad de estilo y por la acción verista. Únicamente el dúo cómico entre Perico y Nicasia ("Ya verás cuando me ponga") rompe la unidad 
de estilo de la partitura, logrando de esta manera el máximo equilibrio en cuanto a la tensión se refiere con el número anterior que canta Rafael "La roca fría del Calvario".

\section{LA CRÍTICA EN LA OBRA DE SERRANO}

Morales San Martín, crítico de El Mercantil Valenciano, describía lo que representaba la figura de José Serrano en el panorama lírico español y lo comparaba con la gran mayoría de los autores teatrales del momento. Para San Martín, Serrano es un compositor dotado de gran técnica, honesto, hijo de la mejor tradición española, ajeno al decantismo nacional y extranjero que ofrece a los espectadores obras maestras del género. De ahí que se producción fuese menguando conforme él maduraba como artista:

¿Qué representa Serrano en el momento actual de la música española? Casi nada: ser el único - ¡léase bien: el único! - representante de aquella inmortal escuela de músicos inspirados, de originalidad lozana, inmarcesible, impregnados del sano humorismo netamente español que se llamaron Barbieri, Arrieta, Oudrid, Gaztambide, Caballero, Chapí, y cuyas obras de sencilla técnica, sin alambicamientos ni quintas esencias del decadentismo extranjero en boga, por su idealismo y por su sentimentalidad son trozos del alma española, fragmentos de la raza ibera llevados a las partituras.

(...)

No vamos a incurrir en la vulgaridad de comparar a Serrano con ningún otro músico español. Pero sí debemos decir que es el único cuyas obras viven por inspiración propia, por su potente y elevada originalidad y su lirismo arrebatador, que conmueve y electriza a los públicos.

(...)

Serrano es de otra estirpe artística, y lo demuestran la nobleza y novedad de sus temas musicales, el verismo del medio ambiente musical descrito en sus partituras y el ningún afán de acaparar con sus obras las taquillas de los teatros. Decía Gustavo Flaubert que una obra maestra sólo la puede producir el genio cada cuatro años lo más pronto. Quizá Serrano ignora la frase de Flaubert; pero instintivamente la aplica a su labor. Sigan los $<$ genios al uso $>$ produciendo sin cesar obras y más obras durante una temporada que viven lo que tardan en estrenarse. Serrano produce sin prisas, pero cuando llega un día y estrena su obra, vive días y días, temporadas y temporadas en los teatros de España y América, sencillamente porque su conciencia de artista sólo le permite dar al público obras dignas, ejemplares, obras maestras, en una palabra. ${ }^{17}$

17 MORALES SAN MARTÍN (1925).
Las zarzuelas de José Serrano fueron recogidas por los principales medios de prensa madrileños como El Imparcial, La Correspondencia de España, El Heraldo de Madrid, La Voz y El País. Entre sus más distinguidos críticos se encuentran José de Laserna, del diario Imparcial; Alonso Algarroba y José Alsina, de El País; Caramanchel y José Álvarez Arranz, de La Correspondencia de España y Alejandro Saint-Aubin y Téllez Moreno, de El Heraldo de Madrid. Como cronistas secundarios hay que citar a Arnedo, S. Oria, J. Moyrón y Diego Cortado (El País), G. Plaza y Vanós (El Heraldo de Madrid) y Carlos Bosch (El Imparcial).

En Valencia cabría destacar a los cronistas Morales de San Martín y a Mascarilla (pseudónimo de José María López), ambos de El Mercantil Valenciano. También el diario Las Provincias plasmó en sus columnas los detalles de los esperados estrenos del maestro.

En cuanto a firmas, se prodigaron una parte importante de los primeros espadas de la crítica madrileña, como José de Laserna, Caramanchel y Saint-Aubin; y de la valenciana: Mascarilla y Bernardo Morales de San Martín.

La música de José Serrano es muy bien acogida en general. En ocasiones se le identifica como el principal continuador de la gran música española, heredero de la mejor tradición de los Barbieri, Oudrid, Gaztambide, Chapí, Chueca, Arrieta y Caballero. En otras se valora su aliento dramático, su facilidad melódica y su impecable técnica al servicio siempre del lirismo, así como su rechazo a introducir en sus obras los lenguajes psicalípticos y los ritmos ligeros americanos. También se elogia la rica instrumentación del maestro, enemiga de los efectos fáciles y conocedora de los procedimientos compositivos modernos, muy en la línea de los grandes autores valencianos como Salvador Giner, Vicente Peydró y Vicente Lleó.

Menos localista y especializado en el cultivo de la nota típica del país, la música del maestro Serrano no es, a primera vista, tan valenciana como la de otros compositores de la región de la Albufera. Como músico de gran personalidad y caudalosa vena interior, no tuvo necesidad de pedir a lo exterior la inspiración prestada del tema popular y del folklore, reduciéndose a tener que moverse en el cuadro estrecho del costumbrismo regional. Lo valenciano, y aún mejor, el espíritu mediterráneo y levantino, alientan y animan su obra, elevando a la categoría de término general; esto es, en la claridad, la gracia, la delicadeza, el lirismo de su temperamento musical y en la luminosidad sonriente de su estilo.

Para él las cosas serias fueron escribir partituras de zarzuela dentro de la mejor tradición del género, perfectas y acabadas; conseguir un estilo; traducción impecable de su temperamento de compositor, el suyo e inconfundible, y es- 
trenar su obras con la seguridad, -difícil de lograr como él lo consiguió certeramente-, del mejor éxito posible.

El compositor nacido en Sueca era, tal como afirmaba Chavarri, un músico de escena y para la escena. Dotado de un alto instinto teatral nunca fallaba en la secuenciación de las escenas dramáticas, así como en la distribución a la perfección de los distintos números musicales que conformaban la obra.

No fue un renovador. Serrano no aporta nada nuevo al mundo de la zarzuela. Empero, no obstante supo adaptar a su inconfundible sello personal los distintos ambientes populares y recoger de cada uno aquello que más le interesaba.

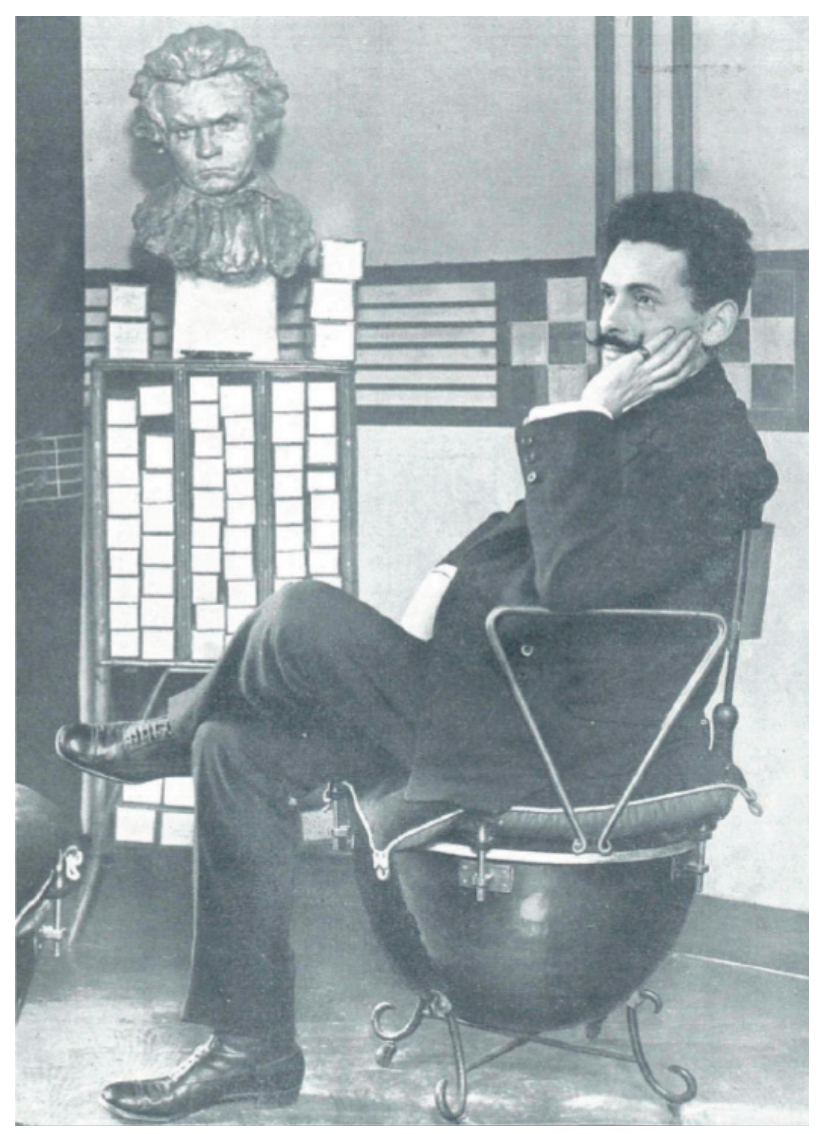

Figura 1. El maestro José Serrano posa para una fotografía con el busto de Beethoven al fondo. La Esfera, 02.05.1914.

\section{BIBLIOGRAFÍA}

Barrera Maraver,Antonio, Crónicas del género chico y de un Madrid divertido, Madrid, Editorial El Avapiés, 1983.

Blasco Magraner, José Salvador, La zarzuela costumbrista, La Laguna, Sociedad Latina de Comunicación Social, Cuadernos de Bellas Artes (CABA), Universidad de La Laguna, 2012.

Díaz Gómez, Rafael, "Serrano Simeón, José”, en Emilio Casares Rodicio (dir.), Diccionario de la música valenciana, Madrid, Iberautor promociones cultural, Instituto Valenciano de la música, 2006.

Montijano Ruiz, Juan José, Historia del Teatro olvidado: La Revista (1864-2009), Granada, Universidad de Granada, 2009. [Tesis Doctoral]

Sagardia, Ángel., El compositor José Serrano (vida y obra), Madrid, Sala Editorial, 1972.

Zurita, Marciano, Historia del género chico, Madrid, Prensa Popular, 1920.

\section{PRENSA CONSULTADA}

Asensio Mas, Ramón: "Cómo escriben los autores. El maestro Serrano", en Madrid Cómico, 11.02.1911.

Morales San Martín, Bernardo, "El maestro Serrano", en El Mercantil Valenciano, 16.05.1925.

Peydró Díez, Vicente, La gatita blanca y La fiesta de la campana (continuación), "Recuerdos de un músico viejo", en El Mercantil Valenciano, 25.10.1931.

La Esfera, 02.05.1914.

Nuevo Mundo, 22.02.1929.

Nuevo Mundo, 12.04.1929.

Las Provincias, 09.03.1941.

Las Provincias, 11.03.1941.

La Vanguardia Española, 11.07.1971.

\section{ARCHIVOS Y HEMEROTECAS CONSULTADOS}

Hemeroteca Municipal de Valencia. Biblioteca de Compositores Valencianos.

Biblioteca Nacional de España.

Recibido: 29.04 .2016

Aceptado: 06.06.2016 